\title{
INGESTÃO E HÁBITOS ALIMENTARES DE PRÉ-ESCOLARES DE TRÊS CAPITAIS DA AMAZÔNIA OCIDENTAL BRASILEIRA: UM ENFOQUE ESPECIAL À INGESTÃO DE VITAMINA A ${ }^{1}$
}

\author{
Helyde Albuquerque MARINHO² e Maria José RONCADA ${ }^{3}$.
}

\begin{abstract}
RESUMO - Com objetivo de avaliar o consumo de energia, vitamina A, zinco e proteínas, bem como os hábitos alimentares de pré-escolares das capitais de Roraima (Boa Vista),Amazonas (Manaus) e Rondônia (Porto Velho) foi realizado um inquérito alimentar em 54, 238 e 78 crianças de ambos os sexos (sub-amostra de inquérito nutricional mais abrangente),respectivamente, em creches e pré-escolas, mediante os métodos recordatório de 24 horas e de freqüência de consumo de alguns alimentos fontes de vitamina $\mathrm{A}$, em entrevista com a mãe ou responsável pela criança. Os resultados mostram que os alimentos mais consumidos foram pão, bolacha e biscoito, com $98,3 \%$, seguidos pelo açúcar $(95,1 \%)$, arroz $(92,4 \%)$, óleo vegetal $(86,0)$, farinha de mandioca $(77,4 \%)$, tomate $(70,1 \%)$ e café $(69,5 \%)$. O consumo de alimentos de origem animal foi responsável por quase dois terços do total ingerido de vitamina $\mathrm{A}$. Quanto à distribuição dos alimentos fontes de vitamina A, observou-se semelhança do seu consumo nas três cidades estudadas. O percentual de adequação de consumo evidenciou que a proteína foi o único nutriente consumido em níveis superiores à recomendação da "National Research Council", enquanto o aporte dietético de vitamina A foi de $84,0 \%, 68,4 \%$ e 63,8\%, em Boa Vista, Manaus e Porto Velho, respectivamente, com inadequação, inclusive, para energia e zinco. Observou-se um padrão alimentar monótono e limitado, com baixo consumo de fontes de vitamina A pré-formada, de hortaliças e de frutas fontes de carotenóides pró-vitamínicos A típicos da Região Amazônica, como buriti, tucumã, pupunha e manga, quase todas sazonais, que não estavam na sua época por ocasião do inquérito.
\end{abstract}

Palavras-chave: Vitamina A; Avaliação dietética; Deficiência de vitamina A

\section{Dietary intake and food habits of pre-scholars in three capitals of Brazilian Western Amazônia: a special approach on vitamin A consumption ${ }^{1}$}

\begin{abstract}
The objective of this study was to evaluate the intake of energy, vitamin A, zinc and protein, as well as food habits of 54, 238 and 78 pre-school children of both sexes, 3 to 6 years old, (wide hange of subsample of inquiry including nutritional), in the capitals of Roraima (Boa Vista),Amazonas (Manaus) and Rondônia (Porto Velho), respectively. Dietary assessments were performed with the parents or someone responsible for the child, using the 24 hour recall and food frequency questionnaire methods. Our results showed that bread, crackers and cookies were the most consumed foods $(98,3 \%)$, followed by sugar $(95,1 \%)$, rice $(92,4 \%)$, vegetable oil $(86,0)$, manioc flour $(77,4 \%)$, tomato $(70,1 \%)$ and coffee $(69,5 \%)$. The intake of animal products was responsible for almost $2 / 3$ of the total intake of vitamin A. The pattern of vitamin A sources consumption among the three cities was similar. Protein was the only nutrient in which the intake exceeded the recommendation, whereas zinc and energy intake were inadequate. Additionally, the consumption of vitamin A was, respectively, $84,0 \%, 68,4 \%$ and $63,8 \%$ in Boa Vista, Manaus and Porto Velho, of the recommended values. A monotonous and limited dietary pat-
\end{abstract}

\footnotetext{
${ }^{1}$ Apoio financeiro do $\mathrm{CNPq}$

${ }^{2}$ Instituto Nacional de Pesquisas da Amazônia - INPA, E-mail: marinho@inpa.gov.br

${ }^{3}$ Faculdade de Saúde Pública da Universidade de São Paulo-USP
} 
tern was observed, with low consumption of pre-formed vitamin A, vegetables and typical regional Amazonian fruits that are sources of carotenoids with vitamin A activity, such as buriti, tucumã, pupunha and mango, all of them seasonal fruits, that were not available during the application of the questionnaire.

Key-words: Vitamin A; Dietary assessment; Vitamin A deficiency

\section{INTRODUÇÃO}

Os inquéritos alimentares aplicados em indivíduos e grupos humanos são instrumentos de grande valor para conhecer a situação nutricional e alimentar, a cadeia causal da desnutrição, as principais características da alimentação relacionada ao aporte de energia, a presença, a quantidade e o equilíbrio dos nutrientes, a adequação com o estado fisiológico do sujeito, a variação e a combinação alimentar e também para informar o direcionamento de políticas de diversos setores para corrigir as anormalidades detectadas (Madrigal-Fritsch et al., 1993).

O Brasil priorizou entre as diretrizes da Política Nacional de Alimentação e Nutrição (PNAN) a redução da desnutrição por micronutrientes, com ênfase nas carências de vitamina A e ferro. Esse compromisso tem por signatários instituições governamentais, acadêmicas e de pesquisas, sociedades científicas e outras, de forma a se estabelecer ações efetivas na redução dessas carências nutricionais (Ministério da Saúde, 2001).

A vitamina A é um nutriente de vital importância para a saúde humana e de várias espécies animais. É reconhecida sua importância na diferenciação celular, no funcionamento normal dos epitélios, da visão, na morfogênese, na resposta imune, no crescimento. Nos olhos os sinais e sintomas da carência de vitamina A costumam ser muito mais evidentes, e prevalentes; além disso, se não houver tratamento, a marcha progressiva de sua gravidade pode chegar à cegueira irreversível (Sommer, 1989; Sommer et al., 1981; Blomhoff et al., 1992, Congdon et al., 1995; McLaren \& Frigg, 1997). Paradoxalmente, entretanto, é a causa de cegueira de mais fácil prevenção em crianças de todo o mundo (WHO, 1994, 1995).

Em âmbito mundial, a deficiência de vitamina A (DVA) vem se destacando, em segundo lugar, como doença carencial isolada, perdendo apenas para a desnutrição-protéicoenergética (DPE), (muitas vezes associada), chegando a ser problema de alta significância em Saúde Pública, em 118 paises, principalmente os das regiões tropicais e subtropicais, bem como em vários países em desenvolvimento (Oomen et al.,1964; McLaren et al., 1965; Patwardhan, 1969; Brown et al., 1979; Mitra, 1985; Feachen, 1987; WHO, 1995, 1996).

A idade está muito associada a DVA. As crianças pré-escolares constituem o grupo etário mais exposto estando sujeitas as seqüelas dessa carência nutricional (Congdon et al., 1995; WHO, 1996). A DVA afeta, anualmente, entre 100 a 140 milhões de crianças em todo o mundo, sendo que dessas 250 a 500 mil ficam cegas e a metade destas morrem (Underwood, 1996).

No Brasil, estudos pontuais em várias regiões revelaram que a deficiência de vitamina A se enquadra entre as três grandes prioridades de nutrição, ao lado da desnutrição protéicoenergética e das anemias (Batista-Filho \& Rissin, 1993; Gonçalves-Carvalho et al., 1995; Marinho et al., 1991; Prado et al., 1995; Ramalho, 1996; Roncada, 1998; Santos et al., 1996), sendo tratada como questão de Saúde Pública desde 1977 (Lobato, 1988).

Na Amazônia Brasileira a defíciência de vitamina A tem sido observada desde os primeiros estudos nutricionais realizados nessa região (Silva, 1959; Lowenstein,1967). Entretanto, as informações registradas na literatura, procedentes da Amazônia Ocidental Brasileira, sobre a epidemiologia da hipovitaminose A, ainda são escassas (Marinho et al., 1981, 1991). Nesse contexto, este estudo tem como objetivo principal avaliar o consumo de vitamina A, energia, proteína e zinco, bem como os hábitos alimentares de pré-escolares de três capitais da Amazônia Ocidental Brasileira. 


\section{METODOLOGIA}

\section{Região Estudada}

A pesquisa foi realizada no espaço geográfico ocupado pelas três capitais da Amazônia Ocidental Brasileira: Boa Vista, Manaus e Porto Velho.

A população estudada foi constituída por crianças de ambos os sexos, em idade préescolar (3 a 7 anos incompletos).

$\mathrm{O}$ estudo foi realizado em creches e préescolas, considerando que quase $50 \%$ das crianças menores de 7 anos, das cidades médias e grandes do País, freqüentam esses tipos de instituiçoes (MEC/INEP, 1998; Barros et al.,1999).

Inicialmente foi realizado um levantamento cadastral junto às Secretarias Estaduais de Educação, Cultura e Desportos dos Estados de Roraima, Amazonas e Rondônia, com a finalidade de conhecer o universo de estudo, que foi representado por 28440 pré-escolares, de ambos os sexos, matriculados em creches e /ou pré-escolas das redes de ensino oficial e particular das capitais dos três Estados. A rede de ensino municipal de Boa Vista, Manaus e Porto Velho apresentou maior percentual de matrículas $(54,8 \%, 58,8 \%$ e $55,3 \%$, respectivamente), seguida da rede estadual em Boa Vista $(28,4 \%)$ e Porto Velho $(24,5 \%)$, e da rede particular em Manaus (32,1 $\%$ ). Esses dados permitiram o cálculo do tamanho das amostras, representativas de cada cidade, bem como dos sorteios proporcionais (aproximadamente 3\% do universo acima mencionado). Estipulou-se o nível de confiança de $95 \%$ e $5 \%$ de erro, e precisão relativa em torno de $20 \%$, considerando-se as recomendações de amostragem (Lwanga \& Lemeshow, 1991; WHO,1996). Dos 865 préescolares sorteados, 17,8 \% não participaram do estudo, em decorrência de diversos motivos, tais como: viagens, doenças, não comparecimento ao estabelecimento, material biológico insuficiente e dificuldade imposta pela criança no momento da coleta de sangue. Obteve-se, assim, o número amostral final de 711 crianças. A maneira como foi procedida a composição da amostra permitiu que a distribuição dos pré-escolares segundo o sexo e idade fosse representativa da população total das crianças matriculadas naquelas instituições.

Participaram do estudo conduzido de 1997 a 1999, somente os pré-escolares que apresentaram o pedido de autorização (consentimento informado) devidamente assinado pelos pais ou responsável pela criança.

\section{Inquérito Alimentar}

O consumo alimentar foi avaliado nas sub- amostras aleatórias 54, 238 e 78 correspondendo a $60,0 \%, 50,0 \%$ e $53,8 \%$ das amostras de Boa Vista, Manaus e Porto Velho, respectivamente. Neste inquérito foram usados os métodos recordatório de 24 horas, questionário de freqüência de consumo de alguns alimentos fontes de vitamina $\mathrm{A}$ e, também, histórico alimentar para pesquisa dos hábitos alimentares dos pré-escolares, por profissionais devidamente treinados em estudos dessa natureza. Foi realizada entrevista com a mãe ou com o responsável pela criança. Adicionalmente, foi realizada uma entrevista com a encarregada da distribuição da alimentação nos estabelecimentos (creches e pré-escolas) sobre o preparo, preferência e as quantidades dos alimentos servidos às crianças. No método recordatório de 24 horas a pessoa entrevistada foi inquerida sobre a ingestão alimentar da criança durante as 24 horas do dia anterior à entrevista. Medidas caseiras foram utilizadas pelas pessoas entrevistadas para demonstrar quanto a criança comeu e/ou bebeu. No método de freqüência de consumo, questionário dietético simplificado (QDS) de alimentos fontes de vitamina A proposto pelo (IVACG, 1989), foi confeccionado um questionário especificamente elaborado com alimentos identificados fontes de vitamina $\mathrm{A}$ (pré-formada e carotenóides precursores dessa vitamina), encontrados nos estabelecimentos (feiras, mercados e outros) das capitais estudadas. As entrevistadas informavam sobre a freqüência expressa em dias por semana e os tipos de alimentos fontes de vitamina A costumeiramente consumidos pelos préescolares, da seguinte maneira:(1X, 2-4 X e > $5 \mathrm{X}$, por semana). Os alimentos fontes de vitamina A foram categorizados em: baixo 
$(<100)$, moderado $(100-1199)$ e alto $(>1200)$, micro gramas de Equivalentes de Retinol-ER $(\mu \mathrm{g}$ ER) do consumo.

Para o cálculo de adequação de consumo de energia, vitamina A, proteínas e zinco foram utilizadas as recomendações da "National Research Council"(1989), estabelecendo-se $100 \%$ do limite mínimo satisfatório do consumo. Para análise quantitativa de consumo alimentar foi usada a Tabela de composição química de alimentos (FIBGE, 1976). Foi empregado também, o Sistema de Apoio à Decisão em Nutrição (Anção et al., 1997), complementado pela introdução de alimentos regionais (Lehti, 1993; INPA,1998).

O pacote estatístico utilizado para análise dos dados foi o programa desenvolvido por Dean et al., (1997) e adotado pela OMS, EPI INFO, Versão 6.0 4b (1997).

\section{RESULTADOS}

A Tabela 1 e Figura 1 apresentam as freqüências dos alimentos mais consumidos pelos pré-escolares em sub-amostra aleatória: Boa Vista, $60 \%$, Manaus, $50 \%$ e Porto Velho, $53,8 \%$. Os alimentos mais consumidos foram pão, bolacha e biscoito, com 98,3\%, seguidos pelo açúcar $(95,1 \%)$, arroz $(92,4 \%)$, óleo vegetal $(86,0 \%)$, farinha de mandioca $(77,4 \%)$, tomate $(70,1 \%)$ e café $(69,5 \%)$. Embora a cebola tenha sido consumida por $78,2 \%$, sabese que a quantidade "per capita" é ínfima, pois ela é usada como condimento.

Tabela 1 - Freqüência de consumo dos principais alimentos relatados por pré-escolares estudados em três capitais da Amazônia Ocidental Brasileira,1997/99.

\begin{tabular}{|c|c|c|c|}
\hline \multicolumn{2}{|c|}{ Grupos de alimento } & \multicolumn{2}{|c|}{ Capitais } \\
\hline & Boa Vista & Manaus & Porto Velho \\
\hline Cereais e derivados & $\%$ & $\%$ & $\%$ \\
\hline Pão/bolacha/biscoito & 96,3 & 100,0 & 98,7 \\
\hline Arroz & 88,9 & 92,0 & 96,2 \\
\hline Macarrão & 24,1 & 8,4 & 19,2 \\
\hline \multicolumn{4}{|l|}{ Açúcares e doces } \\
\hline Açúcar refinado & 96,3 & 95,3 & 93,6 \\
\hline Guloseimas & 25,9 & 36,5 & 24,4 \\
\hline \multicolumn{4}{|l|}{ Raizes e tubérculos } \\
\hline Mandioca(farinha) & 70,4 & 79,8 & 82,0 \\
\hline Batata inglesa & 11,1 & 19,3 & 6,4 \\
\hline \multicolumn{4}{|l|}{ Leguminosas } \\
\hline Feijão & 51,8 & 68,5 & 50,0 \\
\hline Vagem & 12,9 & 4,2 & 9,0 \\
\hline \multicolumn{4}{|l|}{ Hortaliças } \\
\hline Tomate & 74,1 & 68,4 & 67,9 \\
\hline Cebola & 70,3 & 84,9 & 79,5 \\
\hline Pimentão & 31,5 & 30,7 & 26,9 \\
\hline Couve & 9,3 & 9,7 & 10,3 \\
\hline Repolho & 16,7 & 20,6 & 19,2 \\
\hline Cheiro verde & 35,2 & 42,3 & 38,3 \\
\hline \multicolumn{4}{|l|}{ Refrigerante e outros } \\
\hline Refrigerantes & 40,7 & 46,2 & 30,8 \\
\hline Café & 61,1 & 70,6 & 76,9 \\
\hline \multicolumn{4}{|l|}{ Frutas } \\
\hline Banana & 24,1 & 32,8 & 30,8 \\
\hline Laranja & 20,4 & 18,5 & 11,5 \\
\hline Maçã & 9,2 & 10,5 & 30,8 \\
\hline \multicolumn{4}{|l|}{ Carnes } \\
\hline Carne bovina & 38,9 & 28,6 & 30,8 \\
\hline Frango & 42,6 & 49,2 & 46,2 \\
\hline Peixe & 40,7 & 48,3 & 23,1 \\
\hline \multicolumn{4}{|l|}{ Leite e derivados } \\
\hline Leite & 79,6 & 87,4 & 70,5 \\
\hline \multicolumn{4}{|l|}{ Ovos } \\
\hline Ovo de galinha & 22,2 & 20,6 & 16,7 \\
\hline \multicolumn{4}{|l|}{ Gorduras } \\
\hline Margarina & 51,8 & 48,7 & 41,0 \\
\hline Manteiga & 3,7 & 2,1 & - \\
\hline Óleo vegetal & 83,3 & 87,4 & 87,4 \\
\hline
\end{tabular}

Boa Vista $=54(60 \%) ;$ Manaus $238=(50 \%) ;$ Porto Velho $=78(53,8 \%)$ 


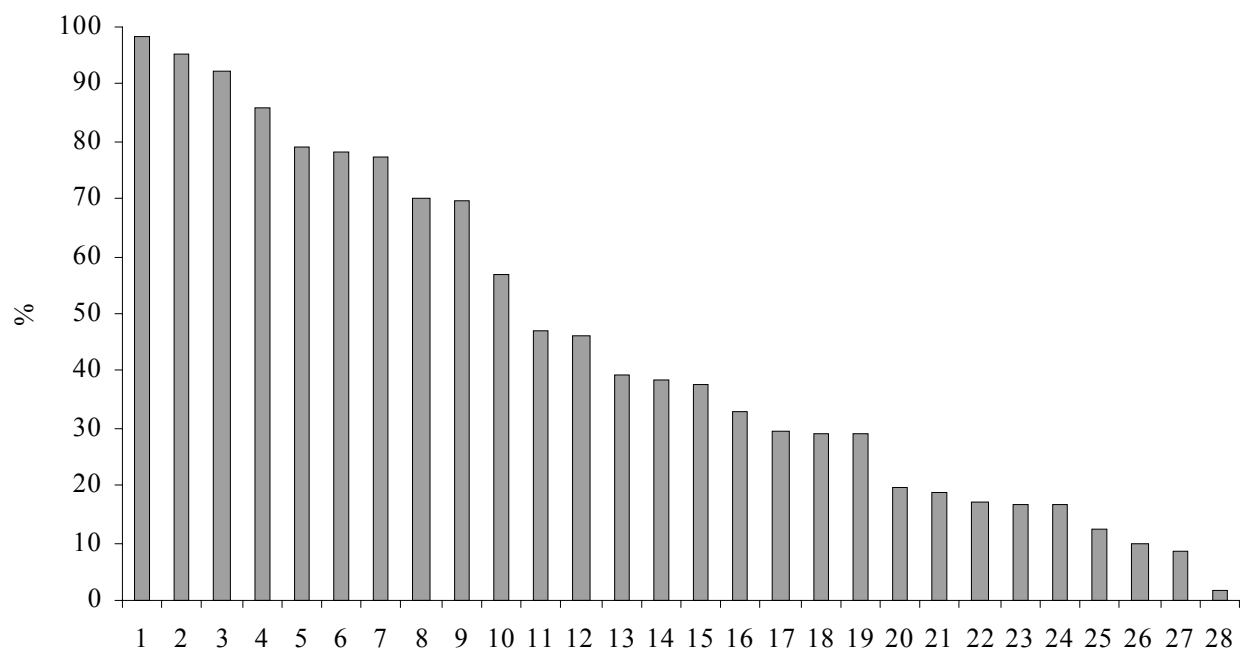

Alimentos

$\begin{array}{llll}1 & \text { Pão /bolacha/biscoito } & 15 & \text { Peixe } \\ 2 & \text { Açúcar refinado } & 16 & \text { Carne bovina } \\ 3 & \text { Arroz } & 17 & \text { Pimentão } \\ 4 & \text { Óleo vegetal } & 18 & \text { Banana } \\ 5 & \text { Leite } & 19 & \text { Guloseimas } \\ 6 & \text { Cebola } & 20 & \text { Ovo de galinha } \\ 7 & \text { Mandioca(farinha) } & 21 & \text { Repolho } \\ 8 & \text { Tomate } & 22 & \text { Macarrão } \\ 9 & \text { Café } & 23 & \text { Maçã } \\ 10 & \text { Feijão } & 24 & \text { Laranja } \\ 11 & \text { Margarina } & 25 & \text { Batata inglesa } \\ 12 & \text { Frango } & 26 & \text { Couve } \\ 13 & \text { Refrigerantes } & 27 & \text { Vagem } \\ 14 & \text { Cheiro verde } & 28 & \text { Manteiga }\end{array}$

Figura 1 - Freqüência de consumo dos principais alimentos relatados por pré-escolares estudados em três capitais da Amazônia Ocidental Brasileira. 1997/99.

Os cereais (pão, bolacha, biscoito e arroz ), a farinha de mandioca e o açúcar foram os principais fornecedores de energia da dieta (Tab. 1 ), contribuindo com $62,1 \%$ para o aporte energético total; entretanto, os resultados da Tabela 2 demonstram haver um "déficit" energético das populações estudadas, pois os pré-escolares de Boa Vista, Manaus e Porto Velho apresentaram adequação média de energia abaixo do nível recomendado: 77,0 \%, 75,9\% e $71,0 \%$, respectivamente. Verificou-se ainda que em relação à adequação do consumo dietético de energia, $31,5 \%, 35,3 \%$ e $27, \%$, das crianças de Boa Vista, Manaus e Porto Velho, respectivamente, haviam consumido menos de $50 \%$ da recomendação de ingestão diária estabelecidas para esse grupo de idade (Tab. 3).

A proteína foi o único nutriente que se mostrou em níveis de adequação superiores a $100,0 \%$ para as crianças das três capitais Boa Vista, Manaus e Porto Velho $(289,6$ \%, 281,8 $\%$ e $131,5 \%$ ), respectivamente(Tab. 2). Esta mesma tabela mostra uma inadequação dietética de zinco.

A ingestão média de vitamina $A$ foi abaixo da recomendada. Em Boa Vista, foi observada cerca de $84,0 \%$ de adequação ; em Manaus, 68,4\%; e em Porto Velho, apenas $63,8 \%$.Observou-se baixo consumo de frutas e hortaliças fontes de vitamina A (Tab. 2). A adequação de consumo de vitamina A mostrou que $9,2 \%, 22,3 \%$ e $23,1 \%$ dos pré-escolares 
de Boa Vista, Manaus e Porto Velho, respectivamente, haviam consumido menos de $50 \%$ das recomendações para as faixas etárias estudadas (Tab. 3).

A figura 2 mostra que o consumo de alimentos de origem animal é responsável por quase dois terços do total ingerido de vitamina $A$.
O leite foi a principal fonte de vitamina A pré-formada da dieta dos pré-escolares.

No tocante à distribuição dos alimentos fonte de vitamina A observa-se semelhança entre o consumo dos pré-escolares nas três cidades estudadas (Tab. 4). Entretanto, dos alimentos considerados de alto teor de

Tabela 2 - Ingestão média diária, desvio-padrão e percentual de adequação de energia, proteínas, vitamina A e zinco de pré-escolares de três capitais da Amazônia Ocidental Brasileira. 1997/99.

\begin{tabular}{|c|c|c|c|c|c|c|c|c|c|c|c|c|}
\hline $\begin{array}{l}\text { Energia e } \\
\text { Nutrientes }\end{array}$ & \multicolumn{3}{|c|}{$\begin{array}{c}\text { Energia } \\
\text { (Kcal)Adequação(\%) }\end{array}$} & \multicolumn{3}{|c|}{$\begin{array}{c}\text { Proteínas } \\
\text { (g)Adequação(\%) }\end{array}$} & \multicolumn{3}{|c|}{$\begin{array}{l}\text { Vitamina } A(\mu g / E R) \\
\text { Adequação(\%) }\end{array}$} & \multicolumn{3}{|c|}{$\begin{array}{c}\text { Zinco (mg) } \\
\text { Adequação(\%) }\end{array}$} \\
\hline Capitais & $\bar{x}$ & DP & $(\%)$ & $\bar{x}$ & DP & $(\%)$ & $\bar{x}$ & DP & $(\%)$ & $\bar{x}$ & DP & $(\%)$ \\
\hline $\begin{array}{c}\text { Boa Vista } \\
(54)\end{array}$ & 1386,0 & $\pm 499,9$ & 77,0 & 69,5 & $\pm 1,5$ & 289,6 & 378,1 & $\pm 89,9$ & 84,0 & 8,4 & $\pm 2,0$ & 83,7 \\
\hline $\begin{array}{c}\text { Manaus } \\
(238)\end{array}$ & 1249,9 & $\pm 459,8$ & 75,0 & 67,6 & $\pm 2,5$ & 281,8 & 431,9 & $\pm 94,2$ & 68,4 & 6,9 & $\pm 1,7$ & 69,7 \\
\hline $\begin{array}{l}\text { Porto Velho } \\
\text { (78) }\end{array}$ & 1278,0 & $\pm 435,1$ & 71,0 & 31,4 & $\pm 5,2$ & 131,5 & 319,0 & $\pm 84,5$ & 63,8 & 7,4 & $\pm 1,8$ & 74,5 \\
\hline
\end{tabular}

Tabela 3 - Distribuição percentual de adequação dietética para energia, proteínas, vitamina A e zinco de pré-escolares de três capitais da Amazônia Ocidental Brasileira. 1997/99.

\begin{tabular}{|c|c|c|c|c|c|c|c|c|}
\hline \multirow{3}{*}{$\begin{array}{l}\text { Energia e } \\
\text { nutrientes } \\
\text { Capitais }\end{array}$} & \multicolumn{8}{|c|}{ PERCENTAGEM DE ADEQUAÇÃO } \\
\hline & \multicolumn{2}{|c|}{$<50 \%$} & \multicolumn{2}{|c|}{$50-75 \%$} & \multicolumn{2}{|c|}{$76-99 \%$} & \multicolumn{2}{|c|}{$>100 \%$} \\
\hline & $\mathrm{n}$ & $\%$ & $\mathrm{n}$ & $\%$ & $\mathrm{n}$ & $\%$ & $\mathrm{n}$ & $\%$ \\
\hline \multicolumn{9}{|l|}{ ENERGIA } \\
\hline Boa Vista (54) & 17 & 31,5 & 4 & 7,4 & 16 & 29,6 & 17 & 31,5 \\
\hline Manaus (238) & 84 & 35,3 & 36 & 15,1 & 51 & 21,4 & 67 & 28,2 \\
\hline Porto Velho (78) & 20 & 27,0 & 28 & 35,9 & 21 & 25,6 & 9 & 11,5 \\
\hline \multicolumn{9}{|l|}{ PROTEÍNAS } \\
\hline Boa Vista (54) & - & - & - & - & - & - & 54 & 100,0 \\
\hline Manaus (238) & - & - & - & - & - & - & 238 & 100,0 \\
\hline Porto Velho (78) & - & - & - & - & 6 & 7,7 & 72 & 92,3 \\
\hline \multicolumn{9}{|l|}{ VITAMINA A } \\
\hline Boa Vista (54) & 5 & 9,2 & 17 & 31,5 & 23 & 42,6 & 9 & 16,7 \\
\hline Manaus (238) & 53 & 22,3 & 68 & 28,6 & 80 & 33,6 & 37 & 15,5 \\
\hline Porto Velho (78) & 18 & 23,1 & 26 & 33,3 & 29 & 37,2 & 5 & 6,4 \\
\hline \multicolumn{9}{|l|}{ ZINCO } \\
\hline Boa Vista (54) & 9 & 16,7 & 6 & 11,1 & 35 & 64,8 & 4 & 7,4 \\
\hline Manaus (238) & 47 & 19,8 & 100 & 42,0 & 79 & 33,2 & 12 & 5,0 \\
\hline Porto Velho (78) & 14 & 18,0 & 21 & 27,0 & 39 & 50,0 & 4 & 5,0 \\
\hline
\end{tabular}




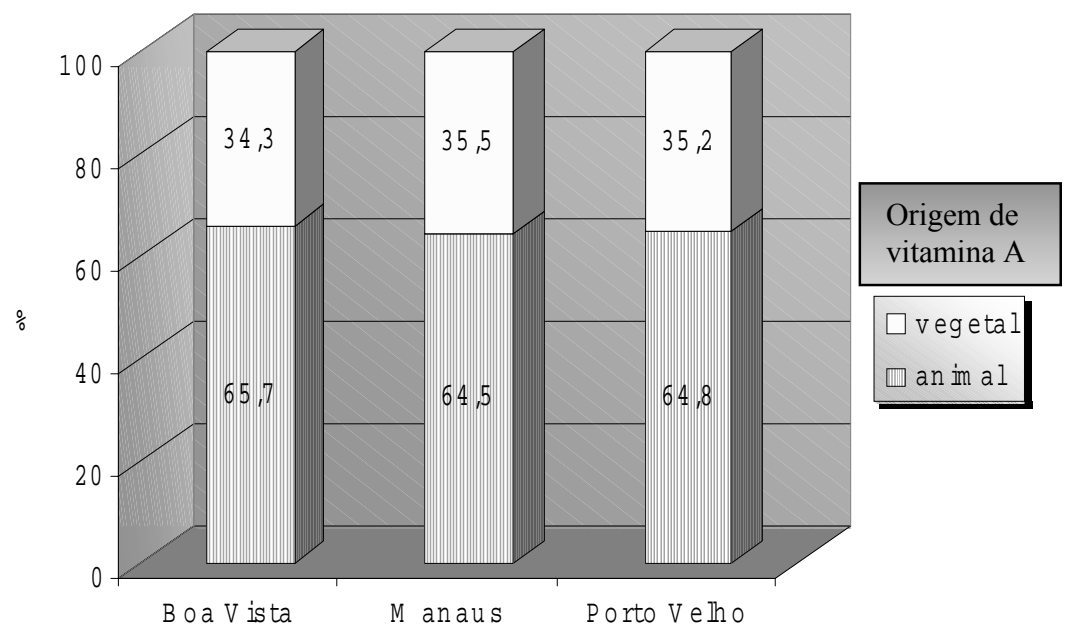

Figura 2 - Distribuição percentual do consumo de vitamina A, segundo a origem dos alimentos (vegetal e animal), dada pelo questionário de freqüência de consumo, de pré-escolares estudados em três capitais da Amazônia Ocidental Brasileira, 1997/99.

vitamina $\mathrm{A}$, foi citado o mais rico - o fígado, apenas por uma criança em Boa Vista e por 8 $(3,4 \%)$ em Manaus, com consumo de uma vez por semana. Das frutas regionais ricas em vitamina A somente o tucumã foi consumido em baixos percentuais nas cidades de Boa Vista e Manaus (Tab. 4). Dos 22 alimentos constantes como fontes de vitamina A, o percentual de freqüência do consumo igual ou superior a 5 vezes por semana foi de farinha de mandioca amarela e o leite de vaca (fontes baixas). Quanto aos alimentos considerados fontes moderadas de vitamina A destacam-se: o cheiro verde, a margarina e os ovos (Tab. 4).

\section{DISCUSSÃO}

A análise da dieta dos pré-escolares do presente estudo em termos de energia, proteína e dos micronutrientes vitamina A e zinco, quando comparados aos padrões de recomendações para a ingestão média, mostram evidências de inadequado consumo médio de energia, vitamina A e zinco; exceção foi a proteína, cuja ingestão ultrapassou em muito os $100 \%$ da recomendação para o pré-escolar.

Esses resultados encontrados confirmam, de modo geral, os da literatura referentes a estudos regionais e nacionais sobre o estado nutricional da população e das crianças (Alencar et al., 1991; Dutra de Oliveira et al., 1998). Os resultados deste estudo mostraram baixa adequação dietética de energia total, e são similares aos encontrados em estudos realizados em pré-escolares do Nordeste (Prado et al., 1995; Ramalho, 1996; Santos et al., 1996). Esta situação de baixo consumo de energia tem um impacto óbvio sobre a adequação protéica, podendo ocorrer um desvio metabólico desse nutriente para o suprimento da carência energética, com prejuízo da sua finalidade plástica(OMS,1985).

No caso da vitamina A os dados dietéticos de 24 horas não são suficientes para afirmar categoricamente o estado nutricional em relação a essa vitamina, considerando a capacidade do organismo poder armazenar grandes quantidades desse nutriente, liberando conforme as necessidades. Atualmente, as informações que cobrem a freqüência de consumo de fontes de vitamina A, incluindo os carotenóides, parecem indicar com mais segurança a ingestão da vitamina.

Quanto à freqüência dos alimentos mais consumidos pelos pré-escolares, o leite, com $79,2 \%$ de ingestão, e a farinha de mandioca amarela com percentual de ingestão de 77,4 \% da população total das três cidades foram as 
Tabela 4 - Freqüência do consumo de alimentos fontes de vitamina A pelos pré-escolares estudados em Boa Vista/RR, 1997/99.

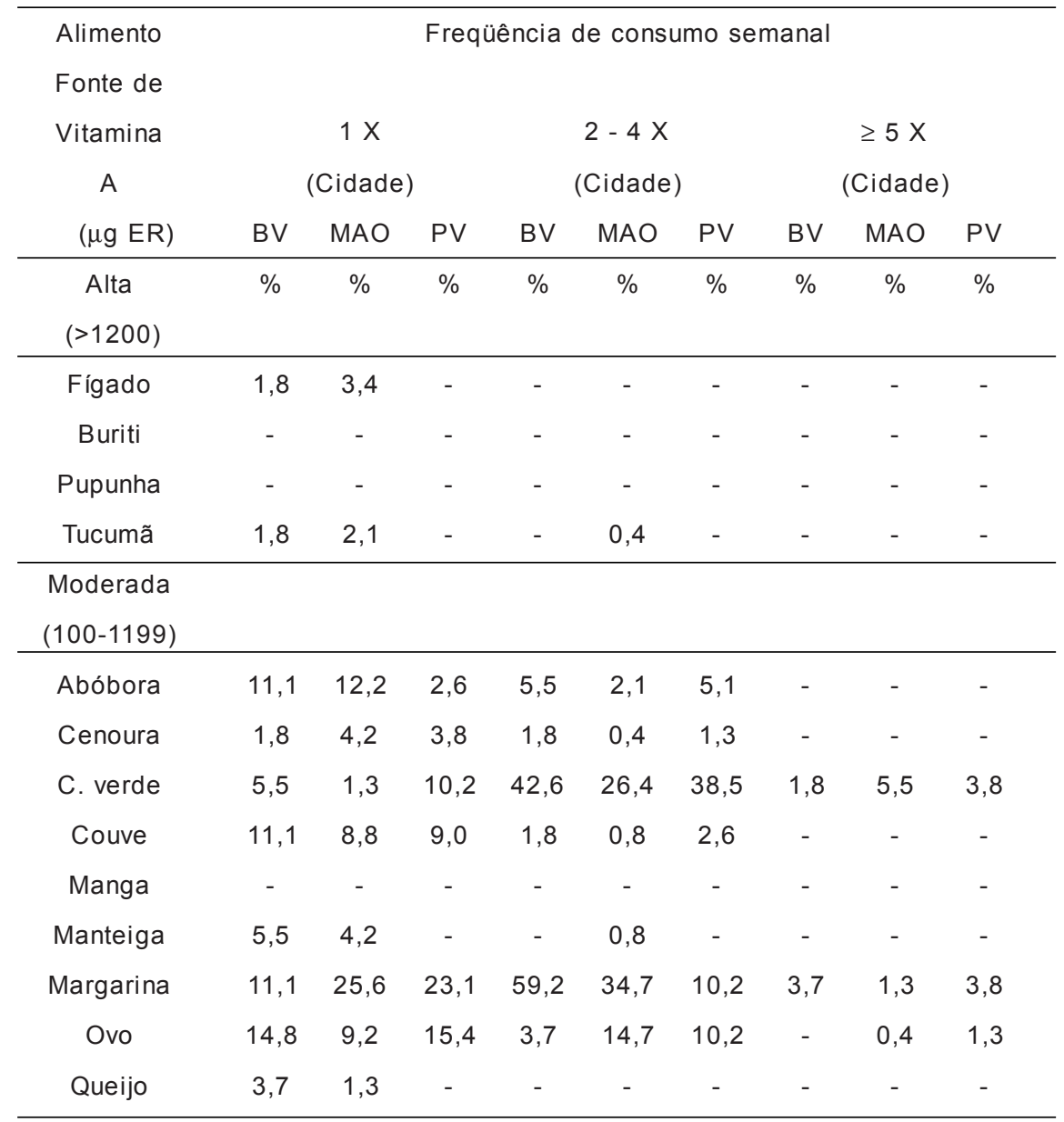

\section{Baixa}

$(<100)$

\begin{tabular}{cccccccccc}
\hline Abacate & - & - & - & - & - & - & - & - & - \\
Açaí & - & - & - & - & - & - & - & - & - \\
Alface & - & - & - & - & - & - & - & - & - \\
Banana & 24,1 & 17,2 & 1,3 & 3,7 & 5,0 & 3,8 & - & - & - \\
F.mandioca & 1,8 & 2,5 & 3,8 & 16,7 & 10,0 & 9,0 & 70,3 & 62,2 & 52,6 \\
Laranja & 1,8 & 7,6 & 1,3 & 16,7 & 9,2 & 6,4 & - & - & - \\
Leite/vaca & 3,7 & 1,3 & 3,8 & 9,2 & 3,4 & 5,1 & 51,8 & 80,7 & 62,8 \\
Peixe & 18,5 & 44,1 & 19,2 & 46,3 & 4,2 & 10,2 & 3,7 & 9,4 & 2,6 \\
Tomate & 3,7 & 10,6 & 3,8 & 64,8 & 50,4 & 24,3 & 16,7 & 5,0 & 3,8 \\
\hline
\end{tabular}


principais fontes de vitamina A. Não foi desprezível, também, o consumo de margarina, outra fonte de vitamina A, num percentual de 47,2\%. Estudos sobre mandioca amarela indicam a presença de carotenóides fontes de vitamina A (Maravalhas, 1964; Marinho \& Arckoll, 1981; Penteado \& Almeida, 1988 ; Marinho et al., 1996).

Os resultados desta pesquisa estão discordantes, em relação à vitamina $\mathrm{A}$, com os achados de Araújo \& Shrimpton (1982), em Manaus. Esses autores não constataram deficiência na ingestão de vitamina A em pré-escolares, sugerindo que o consumo de manteiga e leite em pó, observado no dia do inquérito, contribuiu para a adequação da ingestão de vitamina A. Duarte (1989), também encontrou o consumo médio de vitamina $\mathrm{A}$ adequado; entretanto, verificou que $27 \%$ das crianças não atingiram $100 \%$ de adequação, concluindo que ingestões altas de vitamina $\mathrm{A}$ por algumas crianças elevaram acentuadamente a média de ingestão total dessa vitamina na dieta.

Na Região Amazônica existe uma grande variedade de frutos fontes de carotenóides próvitamínicos A, tais como: buriti, tucumã, pupunha, manga (Aguiar et al., 1980; Yuyama et al., 1991); entretanto, foi extremamente baixo o consumo dos mesmos neste estudo. Talvez a razão tenha sido o fato de serem frutas sazonais que não estavam no seu período de produção na época da coleta dos dados.

A interrelação entre a vitamina $\mathrm{A}$ e o zinco tem suscitado considerável atenção, pois foi constatado que esse mineral influencia em vários aspectos o metabolismo dessa vitamina. A deficiência de zinco está implícita na DPE, associada aos distúrbios metabólicos da vitamina $\mathrm{A}$ e, conseqüentemente, menor síntese de proteína encarregada para o transporte do retinol (proteína ligadora de retinol - RBP- "retinol-binding-protein", e na conversão de retinol-retinal (Christian \& West Jr, 1998).

Quanto à ingestão de zinco, constatouse inadequação nas três cidades, corroborando os resultados encontrados em Manaus por Shrimpton (1980), Araújo \& Shrimpton (1982) Marinho et al(1991) e Yuyama et al (1999) sendo que esses autores verificaram uma inadequação de zinco correspondendo à metade da recomendação, enquanto no presente estudo foi em torno de $76 \%$.

Em geral, os alimentos habitualmente consumidos pelas crianças e os de maior freqüência, neste estudo, praticamente são os mesmos referidos em outros estudos realizados no Estado do Amazonas (Araújo \& Shrimpton, 1982; Duarte, 1989; Marinho, 1989). A ausência de trabalhos publicados, sobre o assunto, em Boa Vista e Porto Velho induz a crer que a situação é semelhante à encontrada em Manaus, ou seja, uma dieta monótona quanto à variedade e baixa quantidade dos alimentos.

A assistência alimentar ao pré-escolar deve ser prioritária, considerando que a qualidade e a quantidade dos alimentos ingeridos são fatores determinantes do seu crescimento e desenvolvimento.

A escassez de profissionais da área de nutrição nas três cidades estudadas provavelmente contribui, em parte, para a falta de orientação às instituições de educação infantil, no sentido de delinearem propostas em relação à formação de bons e prazerosos hábitos alimentares, assim como dietas para crianças em termos de quantidade, qualidade, equilíbrio e adequação às necessidades orgânicas. Sabe-se, que "os hábitos alimentares fazem parte da cultura de um povo e, portanto, é fruto de determinantes culturais e por essa razão, observa-se uma certa resistência das crianças em aceitar alguns alimentos" (Filgueiras, 1995 ). A educação nutricional é, alongo prazo, a melhor estratégia na prevenção das carências nutricionais, combatendo as duas principais causas: a ignorância da população sobre o assunto e a monotonia da dieta. Dada a importância da deficiência de vitamina A no agravo à saúde, sugere-se a promoção ao estimulo do consumo de alimentos de origem vegetal ricos em pró-vitamina $\mathrm{A}$, tão comuns em nosso meio.

\section{BIBLIOGRAFIA CITADA}

Aguiar, J.P.L; Marinho, H.A; Rebelo, Y.S; Shrimpton, R. 1980. Aspectos nutritivos de alguns frutos da Amazônia. Acta Amazônica, 10:755-58. 
Alencar, F.H.; Ferraroni, M.J.R.; Lehti, K.K.; Marinho,H.A; Mota, C.S.; Silva, N.B.; Castro, J.S. 1991. Diagnostico e perspectivas nutricionais na Região Amazônica - In: Bases Cientificas para Desenvolvimento da Amazônia: Fatos e Perspectivas. VI: 145-154.

Anção, M.S; Cuppari, L; Tudisco, E.S; Draibe, S.A; Sigulem, D. 1997. Sistema de apoio a decisão em nutrição. Versão 2.b. São Paulo : Centro de Informática em Saúde da Escola Paulista de Medicina. Mimeografado.

Araújo, D.S; Shrimpton, R. 1982. Padrão alimentar e consumo de zinco, vitamina A e ferro, em pré-escolares num bairro pobre de Manaus 1979. Acta Amazonica, 12: $591-7$.

Barros, A.J.D; Gonçalves, E.V; Borba, C.R.S; Lorenzatto, C.S; Motta, D.B ; Silva, V.R.L; Schiroky,V.M. 1999. Perfil das creches de uma cidade de porte médio do sul do Brasil: operação, cuidados, estrutura física e segurança.Cad Saúde Pública;15: 597-604.

Batista-Filho, M.O; Rissin, A. 1993. Deficiências nutricionais :ações específicas do setor saúde para seu controle. Rio de Janeiro. Cad Saúde Pública, 9:130-35.

Blomhoff, R; Green, M.H; Norum, K.R. 1992. Vitamin A: physiological and biochemical processing. AnnRev Nutr, 12:37-60.

Brown, K.H; Gaffar, A; Alamgir, S.M. 1979. Xerophthalmia, protein-calorie malnutrition and infections inchildren. $J$ Pediatrics, 95: $651-56$.

Congdon, N; Sommer, A; Severns, M.1995.Pupillary and visual threshols in young children as an index of population vitamin A status. Am J Cli Nutr, 61:107682.

Christian P, West KPJr. Interactions between zinc and vitamin $\mathrm{A}$ : an update.Amer $\mathrm{J}$ Clin Nutr1998;68(supll):433S-41S.

Dean, A.G; Dean, J.A; Coulombier, D; Brendel, K.A; Smith, D.C; Burton, A.H. 1997. Epi Info: a word processing, database, and statistics program for epidemiology on micro-computers. Atlanta: Center for Disease Control and Prevention/ Geneva. Word Health Organization.
Duarte, M.R.B.1989. Estudo dos fatores do risco nutricional em crianças matriculadas em pre-escolas das redes de ensino particular, estadual e municipal da cidade de Manaus (AM) em 1997. Avaliação dos inquéritos alimentar, sócio-econômico e cultural. Manaus. Dissertação de Mestrado - Instituto Nacional de Pesquisas da Amazônia - Fundação Universidade do Amazonas, 85p.

Dutra de Oliveira, J.E; Cunha, S.F.C; Marchini, J.S.A. 1998. Carências Nutricionais. São Paulo/SP: Sarvier. 403p.

Feachen, R.G.1987. Vitamin A deficiency and diarrhoea: A review of interrelationships and their implications for the control of xerophthalmia and diarrhoea. Tropical Diseases Bulletin, 84: 15 - 19.

Filgueiras, I.P. 1995. Educação alimentar na préescola: relato de experiência. Comentários. Rev Hig Alim, 9:5.

Fundação IBGE. 1976. Tabela de composição química de alimentos.Estudo nacional de despesas familiar. Rio de Janeiro. V 3.

Gonçalves-Carvalho, C.M.R; Amaya-Farfan, J; Wilke, B.C; Vencovsky, R.1995. Prevalência de Instituto hipovitaminose A em crianças da periferia do Município de Campinas, São Paulo, Brasil. Cad Saúde Pública, 11: 85-96.

Instituto Nacional de Pesquisas da Amazônia - INPA. 1998. Tabela de composição de alimentos da Amazônia. Manaus; INPA.

International Vitamin A Consultative Group.1989. Guidelines for the for development of a simplified dietary assessment to identify groups at risk for inadequate intake of vitamin A: report of international vitamin A. Washington; IVACG

Lehti, K.K.1993. Composição nutricional de alguns alimentos da Amazônia Brasileiraresultados preliminares. Rev Univ AM. Ciên Saúde, 2: 139 - 47.

Lobato, A. 1988. Programas e projetos para controle da hipovitaminose A $\mathrm{n}$ o Brasil . Relatório INAN/ FAO. Brasília (DF). 
Lowenstein, F.W.1967. Report on nutrition surveys in 11 brazilian Amazon communities between 1955-1957. Anais do Simpósio sobre a Biota Amazônica, 6-8.

Lwanga, S.K, Lemeshow, S. 1991. Sample size determination in health studies. Geneva, World Health Organization.

Madrigal-Fritsch, H; Gil-Romo, S. E. P; Romero-Ibarrola, G; Batrouni-Kerkebe, L; Dominguez-Cherit,L; Fetter, I; HernandezAvila, M. 1993. Validacion de Indicadores Qualitativos de Alimentacion: Escala de Guttman VS dieta habitual. Salud Publ $M X, 35: 352-359$.

Maravalhas N. 1964. Carotenóides de Manihot Crantz. In: Maravalhas N. Cinco estudos sobre a farinha de mandioca .Manaus, Instituto Nacional de Pesquisas da Amazônia: Química, 6:35-41.

Marinho, H.A; Arckoll, D.1981. Estudo sobre o caroteno em algumas variedades amazônicas de mandioca (Manihot esculenta Crantz). Acta Amazônica, 11: 515.

Marinho HA. Influência da verminose intestinal (Ascaris lumbricoides e /ou Giardia lamblia) sobre os níveis séricos de vitamina A em crianças recebendo suplementação oral de zinco e/ou vitamina A. Estudo em pré-escolares de um bairro pobre de Manaus. ManausAM. Manaus;1989.[Dissertação de Mestrado-Instituto Nacional de Pesquisas da Amazônia - Fundação Universidade do Amazonas].

Marinho, H.A; França, T.S; Rebelo, Y.S; Shrimpton, R. 1981. Níveis séricos de vitamina A em operários de Manaus Amazonas . Acta Amazônica, 11: 347-53.

Marinho, H.A; Shrimpton, R; Giugliano, R; Burini, R.C. 1991. Influence of enteral parasites on the blood vitamin A levels in preschool children orally suplemented with retinol and / or zinc. Eur J Clin Nutr, 45: 539-44.

Marinho, H.A, Xavier, J.J.B.N; Miranda, R.M; Castro, J.S. 1996. Estudos sobre carotenóides com atividade de provitamina " $A$ " em cultivares de mandioca
(Manihot esculenta Crantz) em ecossistema de terra firme de Manaus, Amazonas, Brasil. Acta Amazônica, 26:127136.

McLaren, D.S; Shirajian, E; Tchalian, M; Khroury, G. 1965. Xerophthalmia in Jordan. Am J Clin Nutr, 17:117 - 20.

McLaren, D.S; Frigg, M. 1997. Sight and Life Manual on vitamin A Deficiency Disorders (VADD)Switzerland,p. $1-139$.

Ministério da Educação e Cultura-MEC/ INEP.1998. Censo Escolar de 1998. Brasília.

Ministério da Saúde. 2001. Política Nacional de Alimentação e Nutrição.

Mitra, M. 1985. Prevalence and determinants of nutritional blindness in Bangladeshi children. WHStat Quart, 38: 317-30.

Oomen, H.A.P.C; McLaren, D.S; Escapini, H. 1964. Epidemiology and public health aspects of hypovitaminosis A. A global survey on xerophthalmia. Trop Geog Med, 16: 271-315.

Organizacion Mundiale de Salud. 1985. Comité mixto FAO/OMS de Expertos em Nutricion Necesidades de energia y de proteínas (Série de Informes Técnicos 724).

Patwardhan, V.N. 1969. Hypovitaminosis A and epidemiology of xerophthalmia. $\mathrm{Am}$ J Clin Nutr, 22: 1106-18.

Penteado, M.V.C; Almeida, L.B. 1988. Ocorrência de carotenóides em cinco cultivares de mandioca (Manhot esculenta Crantz) do Estado de São Paulo. Rev Farm Bioquímica Univ São Paulo 27: 39-49.

Prado, M.S; Assis, A.M.O; Martins, M.C; Nazaré, M.P.A; Rezende, J.F.B; Conceição, M.E.P. 1995. Hipovitaminose A em crianças de áreas rurais do semiárido baiano. Rev Saúde Públ São Paulo 29 4: 295-300.

Ramalho, A. 1996. Diagnóstico do estado nutricional de vitamina A em préescolares atendidos na rede pública de saúde do Município do Rio de Janeiro. In: IV Congresso Nacional da Sociedade Brasileira de Alimentação e Nutrição; 1996 
dez 2-5; São Paulo, Brasil: Sociedade Brasileira de Alimentação e Nutrição, 20p.

Roncada, M.J. 1998. Vitaminas lipossolúveis. In: Dutra - Oliveira JE, Marchini JS. Ciências nutricionais. São Paulo: Sarvier, p; $167-78$.

Santos, L.M.P; Assis, A . M.O; Martins, M.C; Araújo, M.P.N; Morris, S.S; Barreto, M.L. 1996. Situação nutricional e alimentar de pré-escolares no semi-árido da Bahia (Brasil): II- Hipovitaminose A. Rev Saúde Pública 30: 67-74.

Shrimpton, R. 1980. Studies on zinc nutrition in the Amazon Valley. London. Tese de Doutorado-Faculty of Medicine of the University of London].

Silva, W. 1959. Inquérito sobre consumo de alimentos e nutrientes, avaliação do estado nutricional e situação econômica da população amazônica. Bol Com Nac Alim, 42: 13-17.

Sommer, A; Tarwotjo, I; Hussaini, G; Susanto, D; Soegiharto, T. 1981. In c id e n c e, prevalence, and scale of blinding malnutrition. Lancet, 1:1407-8.

Sommer, A. 1989. New imperatives for an old vitamin. Am J Clin Nutr, 119: 96-100.

Underwood, B.A. 1996. Present status and global progreess toward the year 2000 goal. XVII IVACG. Meeting Report.
March 18-22; Guatemala City 26-27.The Nutrition Foundation, Washington, DC.

United States. 1989. National Academy of Sciences. Recommended dietary allowances: report 10 th ed.Washington D C.

World Health Organization. 1994.Using immunisation contacts as the gateway to eliminating vitamin A deficiency. Geneva. (WHO/EPI/GEN / 9-9 REV1).

World Health Organization. 1995. Global prevalence of vitamin A deficiency.Geneva. (WHO/NUT/95, 3),

World Health Organization / UNICEF. 1996. Indicators for assessing vitamin A deficiency and theirapplication in monitoring and evaluating intervention programmes Global prevalence of vitamin A deficiency. Geneva. (WHO/NUT)

Yuyama, L.K.O; Fávaro, R.M.D; Yuyama, K; Vannucci, H. 1991. Biovailability of vitamin A from peach palm (Bactris gasipae H.B.K) and from mango (Mangagifera indica L) in rats. Nutrition Research, 11: 1167-75.

Yuyama, L.K.O; Vasquez, A.L.V; Aguiar, J.P.L; Macedo, S.H.M; Yonekura, L; Nagahama, D.1999. Composição Química e adequação da alimentação oferecida aos pré-escolares de uma instituição beneficiente de Manaus, Amazonas, Brasil. Acta Amazônica, 29: 549-54. 